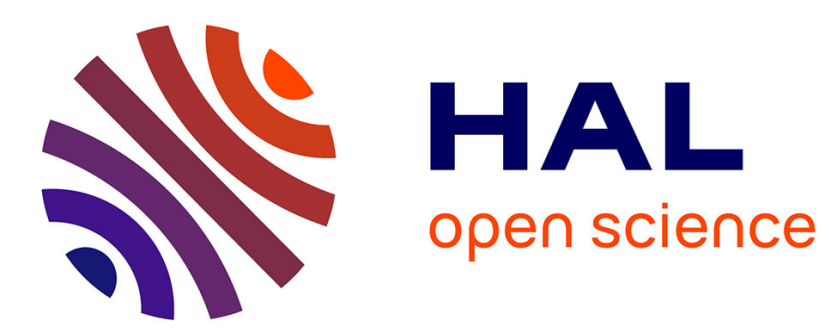

\title{
Localized necking in elastomer-supported metal layers: impact of kinematic hardening
}

Mohamed Ben Bettaieb, Farid Abed-Meraim

\section{To cite this version:}

Mohamed Ben Bettaieb, Farid Abed-Meraim. Localized necking in elastomer-supported metal layers: impact of kinematic hardening. Journal of Manufacturing Science and Engineering, 2017, 139 (6), pp.061008. 10.1115/1.4035183 . hal-01880369

\section{HAL Id: hal-01880369 \\ https://hal.science/hal-01880369}

Submitted on 17 Dec 2018

HAL is a multi-disciplinary open access archive for the deposit and dissemination of scientific research documents, whether they are published or not. The documents may come from teaching and research institutions in France or abroad, or from public or private research centers.
L'archive ouverte pluridisciplinaire $\mathbf{H A L}$, est destinée au dépôt et à la diffusion de documents scientifiques de niveau recherche, publiés ou non, émanant des établissements d'enseignement et de recherche français ou étrangers, des laboratoires publics ou privés. 


\title{
Localized necking in elastomer-supported metal layers: impact of kinematic hardening
}

\author{
Mohamed Ben Bettaieb*, Farid Abed-Meraim \\ LEM3, UMR CNRS 7239 - Arts et Métiers ParisTech, 4 rue Augustin Fresnel, 57078 Metz Cedex 3, \\ France
}

DAMAS, Laboratory of Excellence on Design of Alloy Metals for low-mAss Structures, Université de Lorraine, France

*Correspondence to: Mohamed Ben Bettaieb; E-mail: Mohamed.BenBettaieb@ensam.eu

\begin{abstract}
The present paper deals with localized necking in stretched metal sheets using the initial imperfection approach. The first objective is to study the effect of kinematic hardening on the formability of a freestanding metal layer. To this end, the behavior of the metal layer is assumed to follow the rigid-plastic rate-independent flow theory. The isotropic (resp. kinematic) hardening of this metal is modeled by the Hollomon (resp. Prager) law. A parametric study is carried out in order to investigate the effect of kinematic hardening on the formability limits. It is shown that the effect of kinematic hardening on the ductility limit is noticeably different depending on the strain path considered. The second aim of the paper is to analyze the effect of an elastomer substrate, perfectly bonded to the metal layer, on the formability of the whole bilayer. It is found that the addition of an elastomer layer substantially enhances the formability of the bilayer, in agreement with earlier studies.
\end{abstract}

Keywords Prager's model; freestanding metal layer; metal/elastomer bilayer; formability limit; imperfection approach 


\section{Notations, conventions and abbreviations}

The derivations presented in this paper are carried out using classic conventions. Note that the assorted notations can be combined, while additional notations will be clarified as needed following related equations.

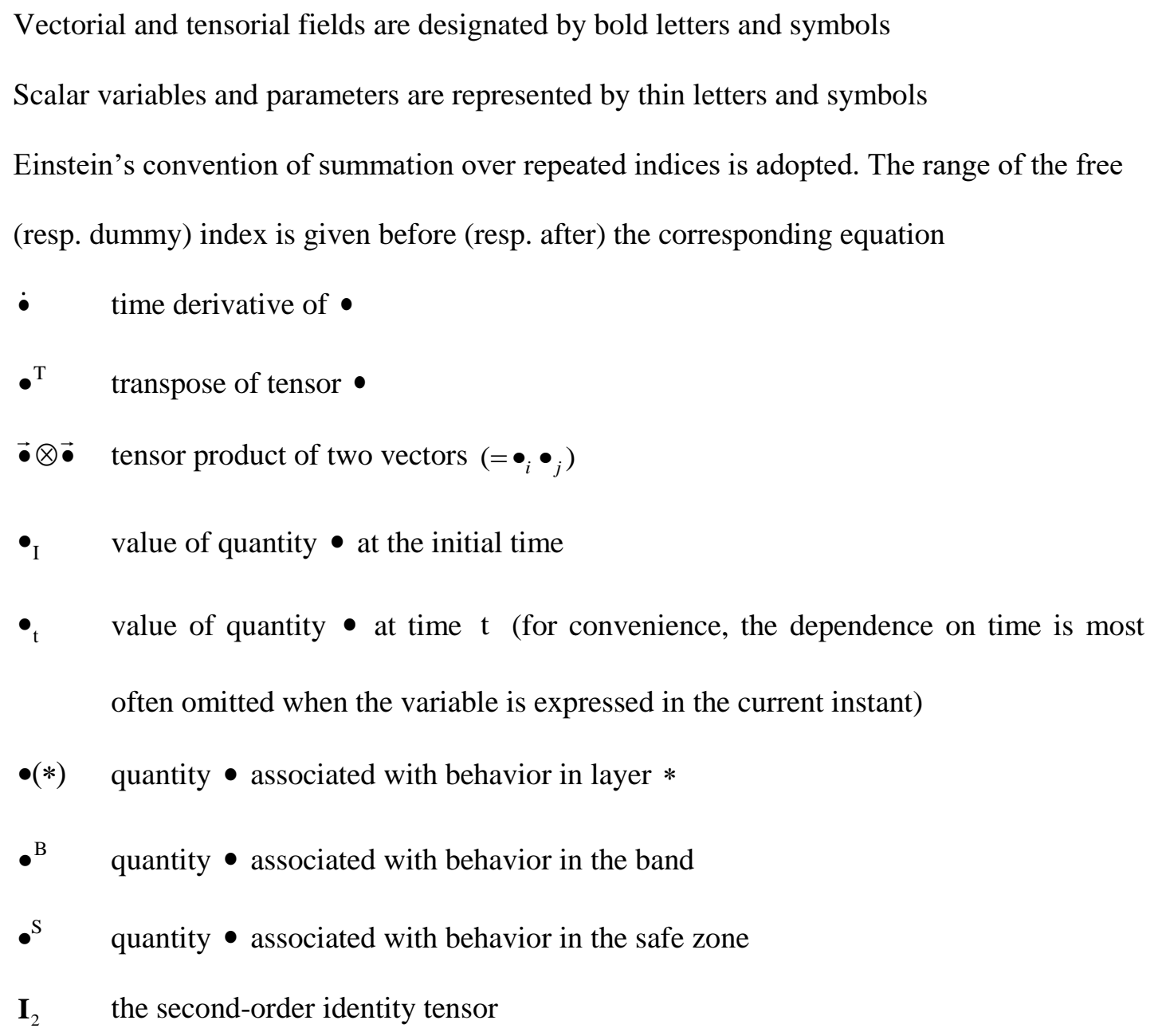

\section{Introduction}

The accurate prediction of localized necking in thin metal sheets still represents an ambitious challenge for the design of structural components in many advanced technology applications, despite the substantial advances and achievements made in this field. The most common representation of this limit of material formability is through the concept of forming limit diagram (FLD). Note that this concept was initially introduced in 1960 s by Keeler and 
Backofen [1] available in the range of positive minor principal strains (i.e., $\varepsilon_{2}>0$ ). The previous work was extended later by Goodwin [2] to the range of negative minor principal strains (i.e., $\varepsilon_{2}<0$ ). The FLDs can be determined experimentally or theoretically (e.g., [3-6]). Because the experimental determination of FLDs has proven to be both expensive and difficult, considerable effort has been expended in prior literature towards the development of reliable theoretical and/or numerical predictive models. It is well known that the formability limit of metal sheets is often strongly influenced by the constitutive behavior and the material parameters of the studied sheet metal [7]. It is demonstrated for example that the ductility increases with the hardening exponent in the case of power-type isotropic hardening [8]. Also, the material viscosity plays an important role in the enhancement of the formability of metallic sheets, as shown in [9] and [10]. The impact of other constitutive features and phenomena on the formability limit has been widely investigated in the literature. In this regard, we can quote the studies of Neale and Chater [11], Cao et al. [12] and Kuroda and Tvergaard [13], aiming at understanding the effect of plastic anisotropy on ductility, as well as the contributions of Haddag et al. [14] and Mansouri et al. [15], concerning the effect of damage-induced softening on the prediction of sheet metal formability. The effect of kinematic hardening on localized necking in biaxially stretched sheets has also been investigated by Tvergaard [16]. However, this earlier study was restricted to loading paths corresponding to the range of positive biaxial stretching (i.e., ranging from plane-strain tension to equibiaxial tension). Also, in that previous investigation, the Ziegler hardening law was used to model the kinematic hardening. More recent works have been carried out in order to investigate the impact of kinematic hardening on the ductility limit of sheet metals. In this regard, we can quote the contribution of He et al. [17], who used the Yoshida-Uemori twosurface kinematic hardening model to assess the effect of kinematic hardening on the onset of localized necking in metal sheets subjected to stretch-bending loading. The same kinematic hardening model has been more recently used in [18] to investigate the effect of nonlinear strain paths on forming limits of stretched metal sheets. In the present work, the localized necking analysis is carried out using an alternative model, namely the Prager kinematic 
hardening law. More specifically, the effect of kinematic hardening (modeled by Prager law) on localized necking in a freestanding metal layer is investigated for the full range of loading paths that span the forming limit diagram (FLD) (i.e., ranging from uniaxial tension to equibiaxial tension).

Due to the theoretically infinite ductility of elastomer materials, bonding an elastomer layer, as substrate, to a freestanding metal layer allows substantially enhancing the ductility of the resulting bilayer. This result has been highlighted by several experimental investigations. However, most commonly conducted experiments are uniaxial tensile tests ([19-21]) or experiments performed under dynamic conditions ([22]). Therefore, the necking instability in substrate-supported metal layers under biaxial loading conditions remains poorly understood so far, and only few theoretical works have been dedicated to this important issue. In this regard, one can quote Guduru et al. [23], who developed a numerical approach, based on the linear stability analysis, in order to predict the ductility of multi-layers under dynamic conditions. Jia and $\mathrm{Li}$ [24] used the bifurcation analysis proposed in [25] to numerically determine the necking limit of substrate-supported metal layers under static in-plane biaxial loading. More recently, Ben Bettaieb and Abed-Meraim [26] investigated the ductility limits of substrate-supported metal layers using both the bifurcation analysis and the initial imperfection approach, initially introduced by Marciniak and Kuczynski [27] and designated hereafter as M-K. In these earlier numerical contributions ([23], [24], [26]), the mechanical behavior of the metal layer follows a rigid-plastic rate-independent model, while plasticity and hardening are assumed to be isotropic. In the current paper, however, the former investigations carried out in [26] are extended to take into account the description of kinematic hardening within the metal layer. In contrast to the earlier investigations based on isotropic hardening models, the current extension allows accurately describing some important physical phenomena, such as the Bauschinger effect. This effect is commonly observed in a number of metallic materials, such as dual phase (DP) steels. To evaluate the ductility of freestanding metal layers and metal/substrate bilayers, the initial imperfection approach will be followed. The main result of the current investigation is that the addition of 
an elastomer substrate can significantly retard the occurrence of localized necking in metal/elastomer bilayers. This confirms the previous studies made without considering kinematic hardening in the constitutive modeling. It is also demonstrated, through several numerical simulations, that kinematic hardening tends to enhance the ductility of the metal/elastomer bilayer.

The reminder of the paper is organized as follows:

- Section 2 outlines the constitutive equations, expressed under an Eulerian formulation, which describe the behavior of the metal and elastomer layers.

- Section 3 details the imperfection approach adopted to predict localized necking in the bilayer. For convenience, Lagrangian formulation is employed to develop the main equations governing this approach.

- Section 4 deals with the algorithmic aspects relating to the powerful numerical tool developed for the prediction of localized necking.

- The various numerical predictions are presented in Section 5, where the effects on localized necking of kinematic hardening and of the addition of an elastomer layer are discussed in details.

\section{Constitutive equations}

\subsection{Metal layer}

The constitutive behavior of the metal layer is assumed to be incompressible, rigid-plastic and obeying the flow theory of plasticity. Accordingly, the plastic flow is defined by the normality law

$$
\dot{\boldsymbol{\varepsilon}}=\dot{\varepsilon}_{\mathrm{eq}} \frac{\partial \mathrm{F}_{\mathrm{p}}}{\partial \boldsymbol{\sigma}},
$$

where $\dot{\varepsilon}_{\text {eq }}$ is the equivalent strain rate and $\mathrm{F}_{\mathrm{p}}$ is the yield function.

The above yield function $F_{p}$ is defined by the following expression:

$$
\mathrm{F}_{\mathrm{p}}=\sqrt{(3 / 2)(\mathbf{S}-\mathbf{X}):(\mathbf{S}-\mathbf{X})}-\sigma_{\mathrm{Y}}
$$


where:

$\mathbf{S}$ denotes the deviatoric part of the Cauchy stress tensor $\boldsymbol{\sigma}$,

$\mathbf{X}$ is the back-stress tensor, which describes the yield surface translation,

$\sigma_{\mathrm{Y}}$ is the yield stress, which measures the evolution of the size of the yield surface.

The isotropic hardening is assumed to follow the Hollomon law [28]

$$
\sigma_{\mathrm{Y}}=\mathrm{K}\left(\varepsilon_{\mathrm{eq}}\right)^{\mathrm{n}}
$$

For the kinematic hardening, the rate of the back-stress tensor $\mathbf{X}$ is assumed to be proportional to the strain rate tensor $\dot{\boldsymbol{\varepsilon}}$, as described by the following linear Prager model [29]:

$$
\dot{\mathbf{X}}=\mathrm{C} \dot{\boldsymbol{\varepsilon}}
$$

The scalars K, n, and C introduced in Eqs. (3) and (4) denote material parameters.

\subsection{Elastomer layer}

The constitutive behavior of an elastomer substrate is described by a neo-Hookean model [30]

$$
\boldsymbol{\sigma}=\mathrm{q} \mathbf{I}_{2}+\mathbf{B} \quad ; \quad \mathbf{B}=\mu \mathbf{V}^{2}
$$

where $\mu$ is the shear modulus, $\mathrm{q}$ is an unknown pressure to be determined by the incompressibility constraint, and $\mathbf{V}$ is the left Cauchy-Green tensor defined by the following relation:

$$
\mathbf{V}^{2}=\mathbf{F} \mathbf{F}^{\mathrm{T}}
$$

with $\mathbf{F}$ being the deformation gradient tensor.

The constitutive framework, developed in Section 2, will be integrated in Section 3 into the equations governing the imperfection approach in order to develop a numerical tool able to predict the onset of localized necking in elastomer-supported metal layers. 


\section{Imperfection approach}

\subsection{Governing equations for the imperfection approach}

The prediction of localized necking in thin substrate-supported metal layers is carried out using the initial imperfection approach, which was originally developed by Marciniak and Kuczynski [27] and designated hereafter as the $\mathrm{M}-\mathrm{K}$ approach. The initial imperfection (in the form of a groove), required for the $\mathrm{M}-\mathrm{K}$ analysis, is assumed to initiate within the metal layer. The elastomer layer is assumed to be initially homogeneous. Fig. 1 depicts the geometry of the bilayer.

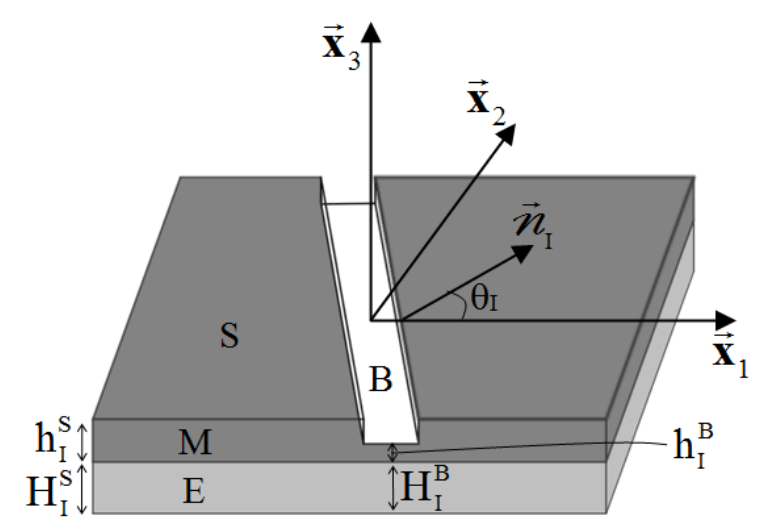

Fig. 1 Illustration of the $\mathrm{M}-\mathrm{K}$ analysis for a bilayer in its initial configuration.

In the sequel, the following notations will be employed:

- $\mathrm{h}_{\mathrm{I}}^{\mathrm{B}}$ : the initial thickness of the metal layer M inside the band $\mathrm{B}$.

- $\mathrm{h}_{\mathrm{I}}^{\mathrm{S}}$ : the initial thickness of the metal layer $\mathrm{M}$ in the safe zone $\mathrm{S}$.

- $\mathrm{H}_{\mathrm{I}}^{\mathrm{B}}$ : the initial thickness of the elastomer layer $\mathrm{E}$ inside the band $\mathrm{B}$.

- $\mathrm{H}_{\mathrm{I}}^{\mathrm{S}}$ : the initial thickness of the elastomer layer $\mathrm{E}$ in the safe zone $\mathrm{S}$ (equal to $\mathrm{H}_{\mathrm{I}}^{\mathrm{B}}$ ).

- $\vec{n}_{\mathrm{I}}$ : the initial unit normal to the band.

- $\theta_{\mathrm{I}}$ : the initial orientation of the band.

The initial imperfection factor $\xi_{\mathrm{I}}$ is defined by the following relation:

$$
\xi_{\mathrm{I}}=1-\frac{\mathrm{h}_{\mathrm{I}}^{\mathrm{B}}}{\mathrm{h}_{\mathrm{I}}^{\mathrm{S}}} .
$$


The $\mathrm{M}-\mathrm{K}$ analysis is characterized by the following assumptions and relations:

- The two layers are assumed to be perfectly adhered (i.e., no delamination is allowed), which can be expressed as follows:

$$
\mathbf{F}^{\mathrm{B}}(\mathrm{M})=\mathbf{F}^{\mathrm{B}}(\mathrm{E})=\mathbf{F}^{\mathrm{B}} \quad ; \quad \mathbf{F}^{\mathrm{S}}(\mathrm{M})=\mathbf{F}^{\mathrm{S}}(\mathrm{E})=\mathbf{F}^{\mathrm{S}},
$$

where $\mathbf{F}^{\mathrm{B}}(\mathrm{M})$ refers to the deformation gradient in the metal layer located within the band zone.

- The kinematic compatibility condition between the band and the safe zone

$$
\mathbf{F}^{\mathrm{B}}=\mathbf{F}^{\mathrm{S}}+\overrightarrow{\mathbf{C}} \otimes \overrightarrow{\boldsymbol{n}}_{\mathrm{I}}
$$

where $\overrightarrow{\mathbf{C}}$ is the jump vector that expresses the discontinuity in the strain field between the band and the safe zone. This jump vector is assumed to be uniform and continuous at the interface between the two layers.

- The equilibrium of the normal and shear forces across the imperfection band is also maintained throughout the deformation

$$
\left(\mathrm{h}_{\mathrm{I}}^{\mathrm{B}} \mathbf{P}^{\mathrm{B}}(\mathrm{M})+\mathrm{H}_{\mathrm{I}}^{\mathrm{B}} \mathbf{P}^{\mathrm{B}}(\mathrm{E})\right) \cdot \overrightarrow{\boldsymbol{n}}_{\mathrm{I}}=\left(\mathrm{h}_{\mathrm{I}}^{\mathrm{S}} \mathbf{P}^{\mathrm{S}}(\mathrm{M})+\mathrm{H}_{\mathrm{I}}^{\mathrm{S}} \mathbf{P}^{\mathrm{S}}(\mathrm{E})\right) \cdot \overrightarrow{\boldsymbol{n}}_{\mathrm{I}},
$$

where $\mathbf{P}$ is the first Piola-Kirchhoff stress tensor related to $\boldsymbol{\sigma}$ by

$$
\mathbf{P}=\mathrm{J} \boldsymbol{\sigma} \mathbf{F}^{-\mathrm{T}}
$$

As the different layers are incompressible, the Jacobian of the deformation gradient $\mathbf{J}$ is equal to 1 all along the deformation for both layers.

- The constitutive equations (1)-(4) for the metal layer and (5)-(6) for the elastomer layer, formulated under the plane-stress conditions, as will be detailed in Section 3.2.

In order to predict the FLD, proportional strain paths are prescribed to the safe zone of the bilayer as follows:

$$
\frac{\dot{\varepsilon}_{22}^{\mathrm{S}}}{\dot{\varepsilon}_{11}^{\mathrm{S}}}=\rho=\mathrm{constant} \quad ; \quad \dot{\varepsilon}_{12}^{\mathrm{S}}=\dot{\varepsilon}_{13}^{\mathrm{S}}=\dot{\varepsilon}_{23}^{\mathrm{S}}=0
$$

The strain ratio $\rho$ is varied in the range $-1 / 2 \leq \rho \leq 1$ to span the complete FLD. 
Exploiting the incompressibility condition of the metal and elastomer layers along with the plane-stress conditions, and making use of Eq. (12), the strain rate tensor in the safe zone can be expressed as [26]

$$
\dot{\boldsymbol{\varepsilon}}^{\mathrm{S}}=\left(\begin{array}{ccc}
\dot{\varepsilon}_{11}^{\mathrm{S}} & 0 & 0 \\
0 & \rho \dot{\varepsilon}_{11}^{\mathrm{S}} & 0 \\
0 & 0 & -(1+\rho) \dot{\varepsilon}_{11}^{\mathrm{S}}
\end{array}\right)
$$

Then, the expression of the deformation gradient in the safe zone $\mathbf{F}^{\mathrm{S}}$ can be easily derived from Eq. (13)

$$
\mathbf{F}^{\mathrm{S}}=\left(\begin{array}{ccc}
\mathrm{e}^{\varepsilon_{11}^{\mathrm{S}}} & 0 & 0 \\
0 & \mathrm{e}^{\rho \varepsilon_{11}^{\mathrm{S}}} & 0 \\
0 & 0 & \mathrm{e}^{-(1+\rho) \varepsilon_{11}^{\mathrm{S}}}
\end{array}\right) .
$$

Combining the compatibility condition (9) and the particular expression (14) of $\mathbf{F}^{\mathrm{S}}$, the deformation gradient in the band can be expressed in the following form:

$$
\mathbf{F}^{\mathrm{B}}=\left(\begin{array}{ccc}
\mathrm{e}^{\varepsilon_{11}^{\mathrm{s}}}+\mathrm{C}_{1} n_{\mathrm{I} 1} & \mathrm{C}_{1} n_{\mathrm{I} 2} & 0 \\
\mathrm{C}_{2} n_{\mathrm{I} 1} & \mathrm{e}^{\rho \varepsilon_{11}^{\mathrm{s}}}+\mathrm{C}_{2} \boldsymbol{n}_{\mathrm{I} 2} & 0 \\
0 & 0 & \frac{1}{\mathrm{e}^{(\rho+1) \varepsilon_{11}^{\mathrm{s}}}+\mathrm{C}_{1} n_{\mathrm{I} 1} \mathrm{e}^{\rho \varepsilon_{11}^{\mathrm{s}}}+\mathrm{C}_{2} n_{\mathrm{I} 2} \mathrm{e}^{\varepsilon_{11}^{\mathrm{s}}}}
\end{array}\right) .
$$

\subsection{Algorithm for the prediction of FLDs}

The general algorithm used to predict the FLD of the metal/elastomer bilayer is based on the following three nested loops: 
For $\rho=-1 / 2$ to $\rho=1$ at user-defined intervals (here, we take intervals of 0.1 ).

For $\theta_{\mathrm{I}}$ spanning the admissible range of inclination angles (i.e., between $0^{\circ}$ and $90^{\circ}$ ), at user-defined intervals (here, we take intervals of $1^{\circ}$ ).

For each time increment $\left[\mathrm{t}_{\mathrm{n}}, \mathrm{t}_{\mathrm{n}}+\Delta \mathrm{t}\right]$, an implicit incremental algorithm is developed and used to integrate the governing equations of the metal and elastomer layers in both the safe zone and the band. The application of this incremental integration scheme is stopped when the following criterion is reached:

$$
\dot{\varepsilon}_{33}^{\mathrm{B}} / \dot{\varepsilon}_{33}^{\mathrm{S}} \geq 10 .
$$

The strain component $\varepsilon_{11}^{\mathrm{S}}$, thus obtained once the criterion (16) is satisfied, is considered to be the critical strain $\varepsilon_{11}^{*}$ corresponding to the current band inclination $\theta$ and strain path $\rho$.

The smallest critical strain $\varepsilon_{11}^{*}$, solution of the above algorithm, over all initial angles $\theta_{\mathrm{I}}$ and the corresponding current angle define, respectively, the necking limit strain $\varepsilon_{11}^{\mathrm{L}}$ and the necking band orientation for the current strain-path ratio $\rho$.

\section{Results and discussions}

This section is divided into two main sections, which correspond respectively to the freestanding metal layer results and the metal/elastomer bilayer results.

\subsection{Freestanding metal layer}

In order to investigate the effect of kinematic hardening on the ductility limit of a freestanding metal layer, a parametric study is conducted in this paper. In this parametric study, four fictitious materials are considered. For each fictitious material, two sets of parameters are considered: the first set corresponds to the isotropic hardening model (without kinematic hardening), while the second is associated with the mixed hardening model (combined isotropic and kinematic hardening). The parameters $K^{(M)}$ and $n^{(M)}$, corresponding to the 
mixed hardening model, are kept identical for all materials (as detailed in Table 1), and only parameter $\mathrm{C}$ (of the Prager model) is varied from one material to another (100 MPa, $200 \mathrm{MPa}$, $300 \mathrm{MPa}$ and $400 \mathrm{MPa}$ ). Once the parameters corresponding to the mixed hardening model are fixed, the hardening parameters $\mathrm{K}^{(\mathrm{I})}$ and $\mathrm{n}^{(\mathrm{I})}$ for the isotropic hardening model are fitted in order to obtain the same uniaxial stress-strain response yielded by the two hardening models for each fictitious material, as shown in Fig. 2. Reference to the metal or elastomer layer is obviously omitted in this section, as only a freestanding metal layer is studied here.

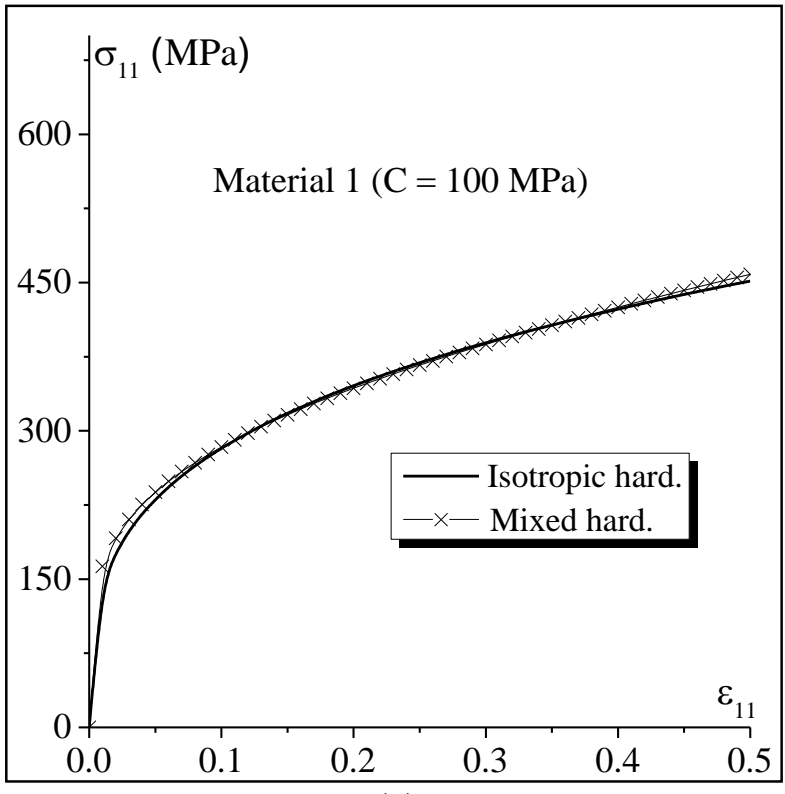

(a)

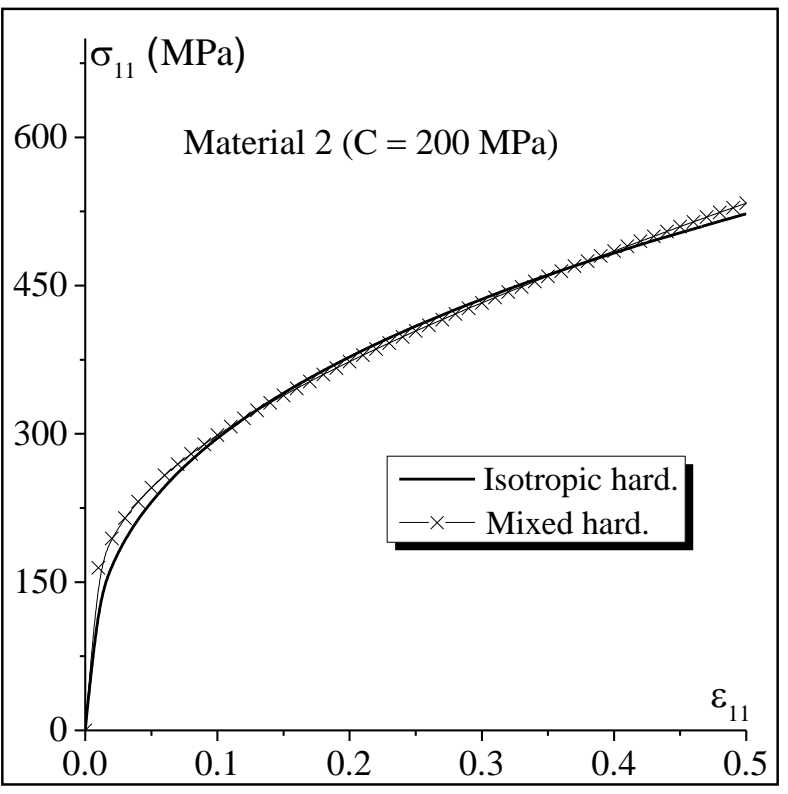

(b) 


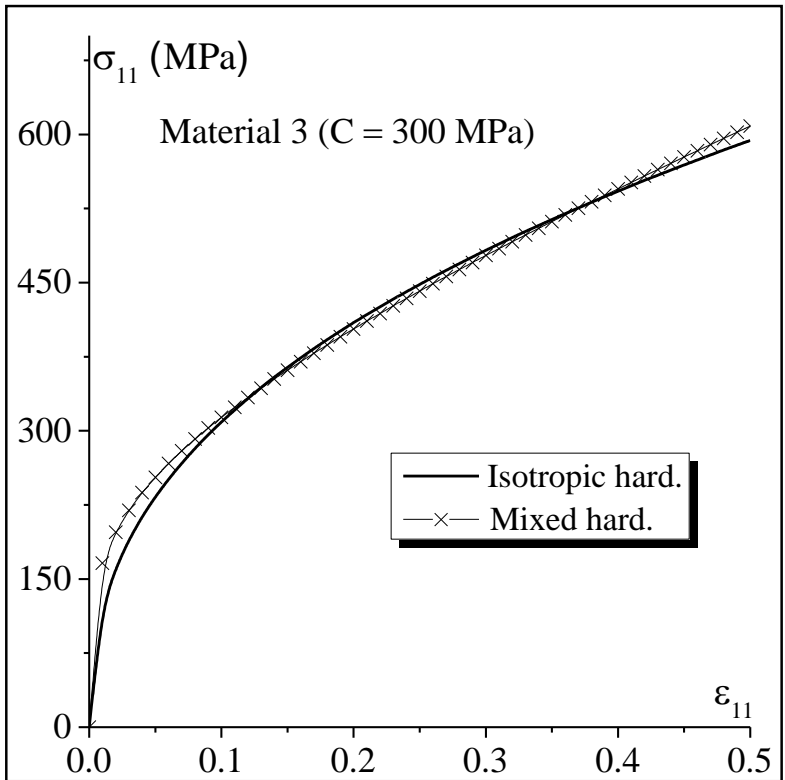

(c)

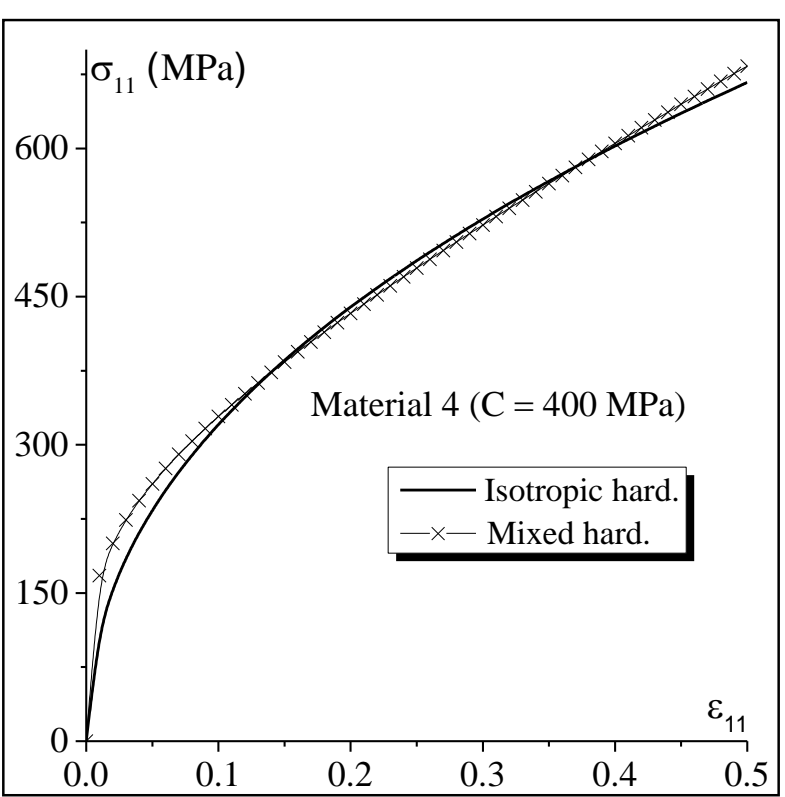

(d)

Fig. 2 Comparison between the stress-strain curves obtained by isotropic hardening and mixed hardening: (a) Material 1 ( $\mathrm{C}=100 \mathrm{MPa}$ ); (b) Material $2(\mathrm{C}=200 \mathrm{MPa})$; (c) Material 3

$$
\text { ( } \mathrm{C}=300 \mathrm{MPa}) \text {; (d) Material } 4(\mathrm{C}=400 \mathrm{MPa}) \text {. }
$$

The material parameters corresponding to all materials for both hardening models are given in Table 1.

Table 1 Hardening parameters

\begin{tabular}{|c|c|c|c|c|c|}
\hline \multirow{2}{*}{} & \multicolumn{2}{|c|}{ Isotropic hardening } & \multicolumn{3}{c|}{ Mixed hardening } \\
\cline { 2 - 6 } & $\mathrm{K}^{(\mathrm{I})}[\mathrm{MPa}]$ & $\mathrm{n}^{(\mathrm{I})}$ & $\mathrm{K}^{(\mathrm{M})}[\mathrm{MPa}]$ & $\mathrm{n}^{(\mathrm{M})}$ & $\mathrm{C}[\mathrm{MPa}]$ \\
\hline Material 1 & 553 & 0.292 & 447 & 0.221 & 100 \\
\hline Material 2 & 668 & 0.354 & 447 & 0.221 & 200 \\
\hline Material 3 & 787 & 0.406 & 447 & 0.221 & 300 \\
\hline Material 4 & 914 & 0.455 & 447 & 0.221 & 400 \\
\hline
\end{tabular}

Before analyzing the effect of kinematic hardening for the whole range of strain paths, attention is first confined to the particular case of plane-strain state $(\rho=0)$. For this strain path, the necking band orientation $\theta_{\mathrm{I}}$ and the normal vector $\overrightarrow{\boldsymbol{n}}_{\mathrm{I}}$ are equal to $0^{\circ}$ and $(1,0,0)$, 
respectively, as demonstrated by many authors (see, for instance, [8]). Hence, Eq. (10) reduces to

$$
\mathrm{h}_{\mathrm{I}}^{\mathrm{B}} \mathrm{P}_{11}^{\mathrm{B}}=\mathrm{h}_{\mathrm{I}}^{\mathrm{S}} \mathrm{P}_{11}^{\mathrm{S}} \text {. }
$$

For this particular case, the strain path remains linear during the deformation both in the safe zone and in the band. The deformation gradient tensors $\mathbf{F}^{\mathrm{S}}$ and $\mathbf{F}^{\mathrm{B}}$ are expressed as follows:

$$
\mathbf{F}^{\mathrm{S}}=\left[\begin{array}{ccc}
\mathrm{e}^{\varepsilon_{11}^{\mathrm{S}}} & 0 & 0 \\
0 & 1 & 0 \\
0 & 0 & \mathrm{e}^{-\varepsilon_{11}^{\mathrm{S}}}
\end{array}\right] \quad ; \quad \mathbf{F}^{\mathrm{B}}=\left[\begin{array}{ccc}
\mathrm{e}^{\varepsilon_{11}^{\mathrm{B}}} & 0 & 0 \\
0 & 1 & 0 \\
0 & 0 & \mathrm{e}^{-\varepsilon_{11}^{\mathrm{B}}}
\end{array}\right] .
$$

By combining Eqs. (11), (17) and (18), one can easily derive the Eulerian form, equivalent to Eq. (17)

$$
\mathrm{h}_{\mathrm{I}}^{\mathrm{B}} \mathrm{e}^{-\varepsilon_{11}^{\mathrm{B}}} \sigma_{11}^{\mathrm{B}}=\mathrm{h}_{\mathrm{I}}^{\mathrm{S}} \mathrm{e}^{-\varepsilon_{11}^{\mathrm{S}}} \sigma_{11}^{\mathrm{S}} \text {. }
$$

On the other hand, the expressions of $\sigma_{11}^{\mathrm{S}}$ and $\sigma_{11}^{\mathrm{B}}$ can be derived by combining the planestress conditions and the constitutive equations of the metal layer

$$
\sigma_{11}^{\mathrm{B}}=2\left(\mathrm{C} \varepsilon_{11}^{\mathrm{B}}+\frac{2^{\mathrm{n}} \mathrm{K}\left(\varepsilon_{11}^{\mathrm{B}}\right)^{\mathrm{n}}}{3^{\frac{\mathrm{n}+1}{2}}}\right) ; \quad \sigma_{11}^{\mathrm{S}}=2\left(\mathrm{C} \varepsilon_{11}^{\mathrm{S}}+\frac{2^{\mathrm{n}} \mathrm{K}\left(\varepsilon_{11}^{\mathrm{S}}\right)^{\mathrm{n}}}{3^{\frac{\mathrm{n}+1}{2}}}\right),
$$

where $\mathrm{C}, \mathrm{K}$, and $\mathrm{n}$ are the hardening parameters. Hence, Eq. (19) can be rewritten as

$$
\mathrm{h}_{\mathrm{I}}^{\mathrm{B}} \mathrm{e}^{-\varepsilon_{11}^{\mathrm{B}}}\left(\mathrm{C} \varepsilon_{11}^{\mathrm{B}}+\frac{2^{\mathrm{n}} \mathrm{K}\left(\varepsilon_{11}^{\mathrm{B}}\right)^{\mathrm{n}}}{3^{\frac{\mathrm{n}+1}{2}}}\right)=\mathrm{h}_{\mathrm{I}}^{\mathrm{S}} \mathrm{e}^{-\varepsilon_{11}^{\mathrm{s}}}\left(\mathrm{C} \varepsilon_{11}^{\mathrm{S}}+\frac{2^{\mathrm{n}} \mathrm{K}\left(\varepsilon_{11}^{\mathrm{S}}\right)^{\mathrm{n}}}{3^{\frac{\mathrm{n}+1}{2}}}\right) .
$$

The strain component $\varepsilon_{11}^{\mathrm{B}}$ is varied between 0 and 1 , with an increment size of $10^{-3}$. For each value of $\varepsilon_{11}^{\mathrm{B}}$, Eq. (21) is solved iteratively, providing the corresponding value of $\varepsilon_{11}^{\mathrm{S}}$. The evolution of the ratio $\varepsilon_{11}^{\mathrm{B}} / \varepsilon_{11}^{\mathrm{S}}$ is plotted in Fig. 3 as a function of $\varepsilon_{11}^{\mathrm{S}}$, for the different materials defined in Table 1. The initial imperfection factor $\xi_{\mathrm{I}}$, which is equal to $1-\left(\mathrm{h}_{\mathrm{I}}^{\mathrm{B}} / \mathrm{h}_{\mathrm{I}}^{\mathrm{S}}\right)$, as stated by Eq. (7), is fixed to $10^{-2}$. The dots tagged on each curve indicate the maximum value of $\varepsilon_{11}^{\mathrm{S}}$, which corresponds to the limit strain $\varepsilon_{11}^{\mathrm{L}}$. Indeed, when the maximum value of 
$\varepsilon_{11}^{\mathrm{S}}$ is reached, the strain rate component $\dot{\varepsilon}_{33}^{\mathrm{S}}$ (equal to $-\dot{\varepsilon}_{11}^{\mathrm{S}}$ in this case) becomes very small compared to $\dot{\varepsilon}_{33}^{\mathrm{B}}$, and criterion (16) is accordingly satisfied. The different curves reported in Fig. 3 indicate that, for this particular plane-strain loading path, the consideration of kinematic hardening tends to increase the limit strain.

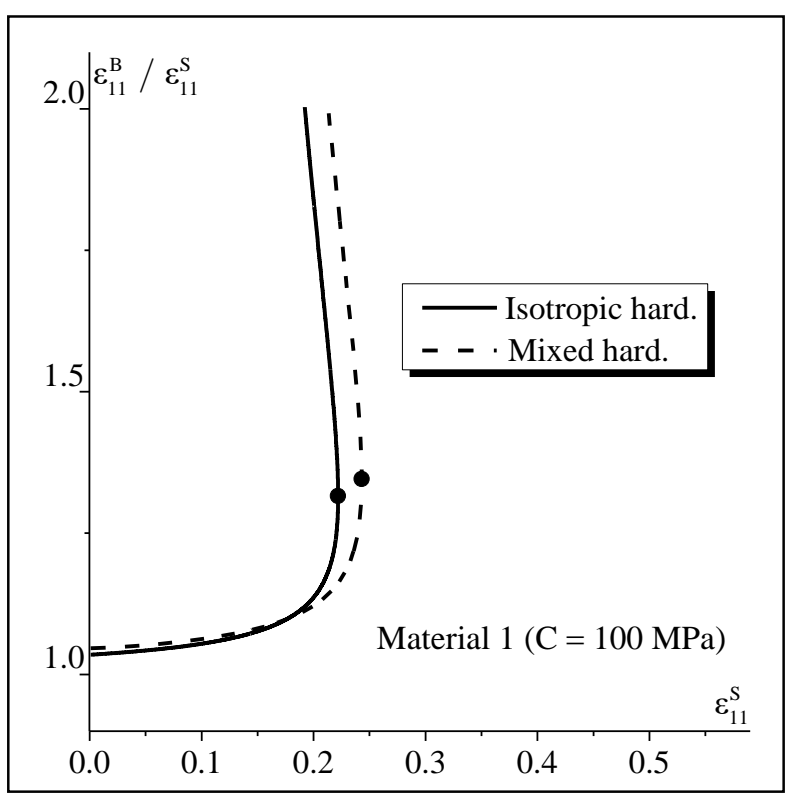

(a)

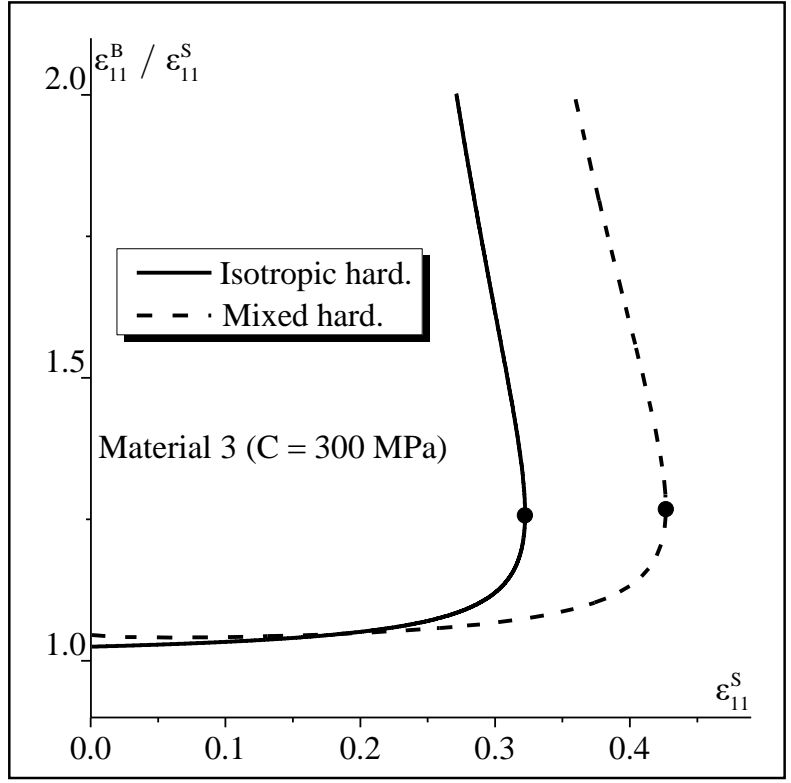

(c)

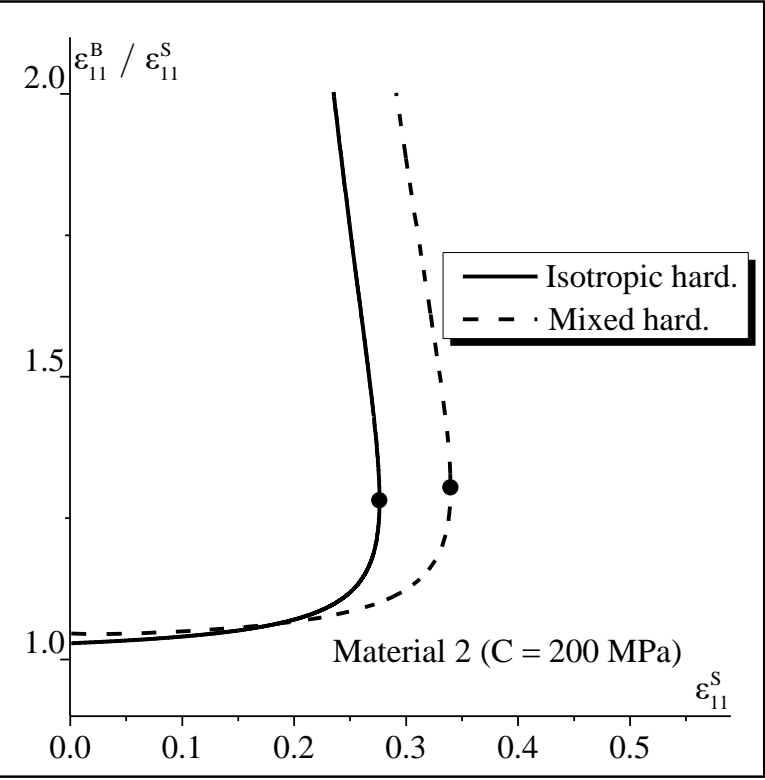

(b)

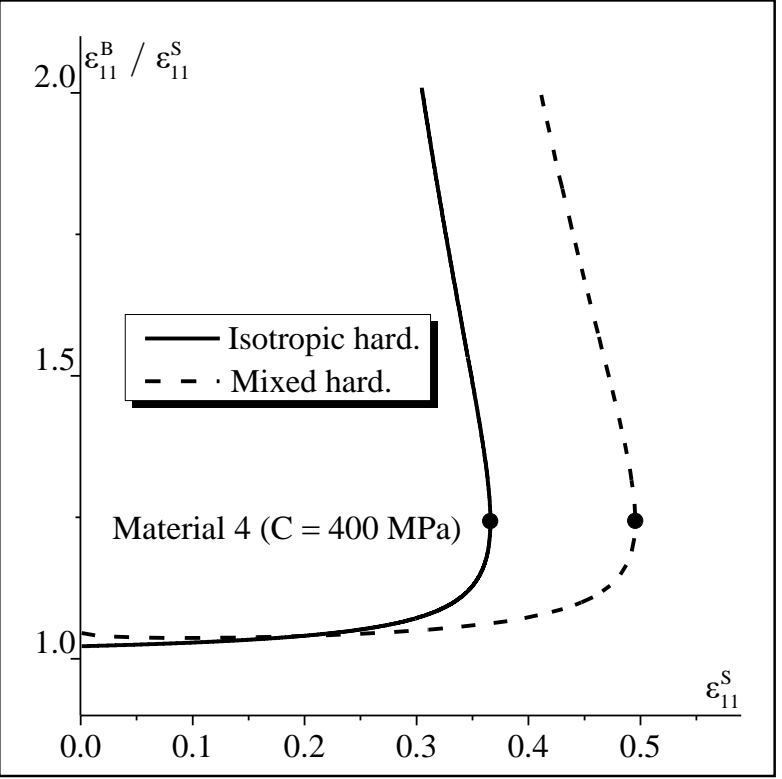

(d)

Fig. 3 Evolution of the strain ratio $\varepsilon_{11}^{\mathrm{B}} / \varepsilon_{11}^{\mathrm{S}}$ as a function of $\varepsilon_{11}^{\mathrm{S}}$ for the plane-strain state (freestanding metal layer): (a) Material 1; (b) Material 2; (c) Material 3; (d) Material 4. 
The influence of the kinematic hardening parameter $\mathrm{C}$ on the shape and the level of FLDs is depicted in Fig. 4. In this figure, the initial imperfection factor $\xi_{\mathrm{I}}$ (i.e., the initial value for the factor defined in Eq. (7)) is equal to $10^{-2}$. From these different curves, the following conclusions can be drawn:

- Despite the similarity of the uniaxial stress-strain curves given by the two hardening models (isotropic and mixed), as shown in Fig. 2, the level and the shape of the associated FLDs differ (see Fig. 3). This difference is due to the fact that the strain path inside the band evolves during the deformation. Indeed, at the beginning of straining, the components of the jump vector $\overrightarrow{\mathbf{C}}$ are very small and, consequently, the deformation gradient and the strain path inside the band are very close to their counterparts outside the band (see Eq. (9)). As deformation progresses, the strain path inside the band gradually deviates from proportionality. Thus, although both hardening models provide the same uniaxial stress-strain response, they yield different mechanical responses inside the band (due to the complexity in the loading path). These differences clearly justify why the predicted limit strains are influenced by the hardening model considered.

- For Material 1, the difference between the FLD predictions corresponding to isotropic and mixed hardening models is relatively small. This is due to the small value of the kinematic hardening parameter $\mathrm{C}$, which induces a small effect of back-stress.

- For the other materials (2, 3 and 4), the effect of kinematic hardening on the limit strain depends on the strain path $\rho$ considered. It is observed that the predicted limit strain is increased for strain paths ranging from -0.5 to 0.5 , while it is lowered in the neighborhood of equibiaxial tension (i.e., $\rho \in[0.5,1]$ ). 


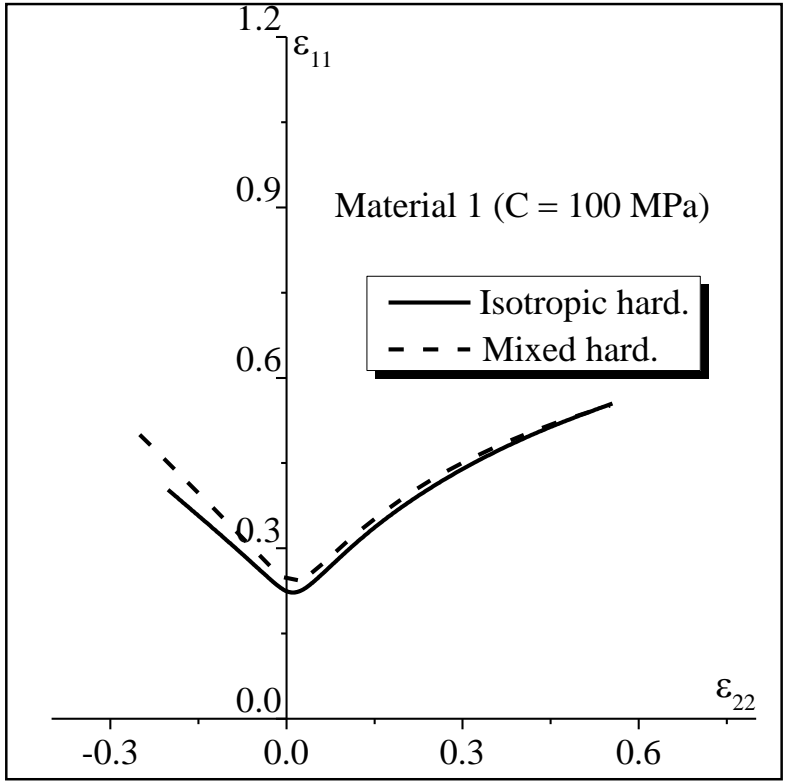

(a)

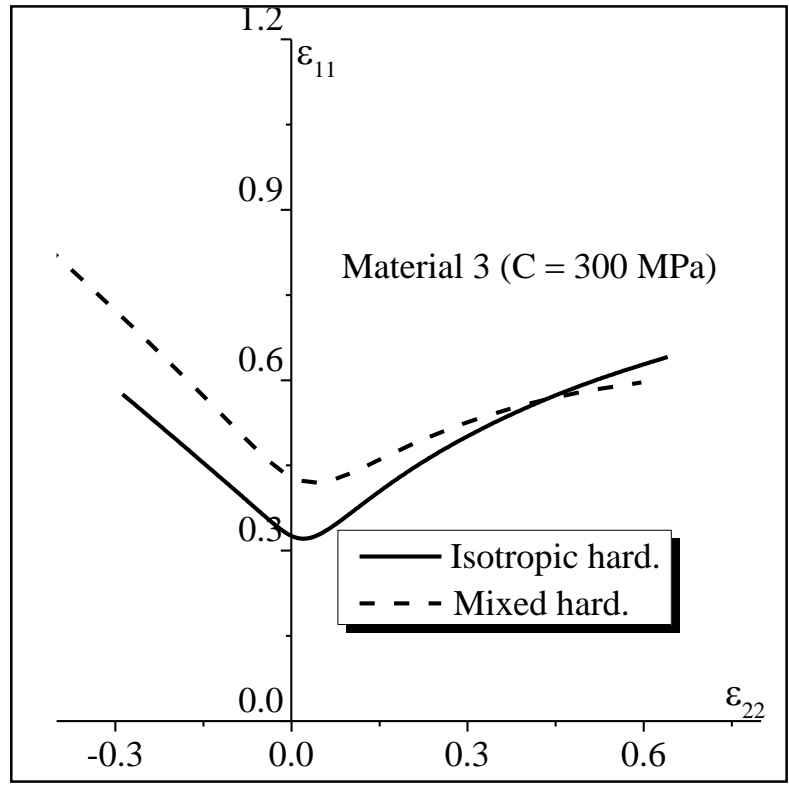

(c)

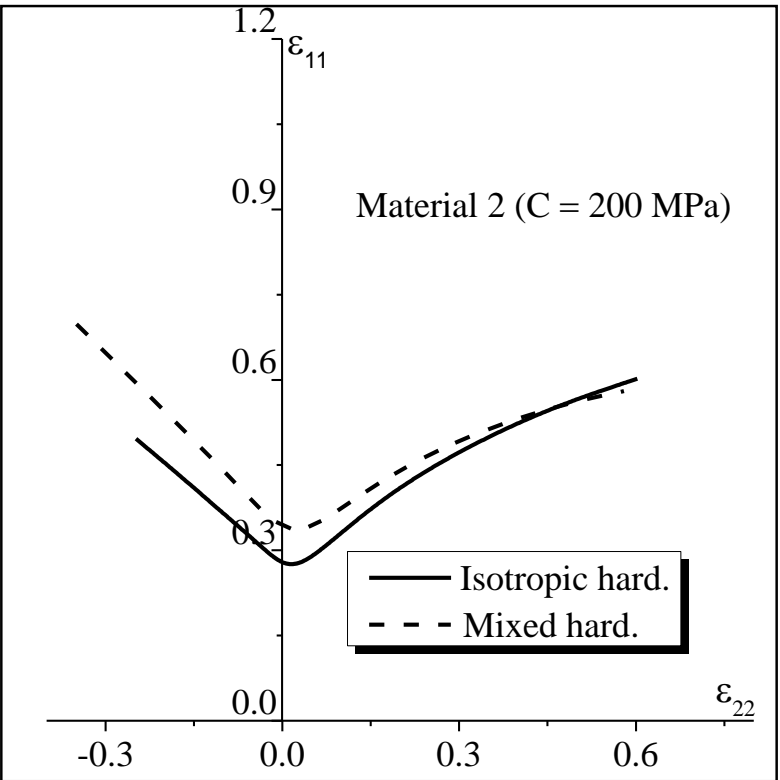

(b)

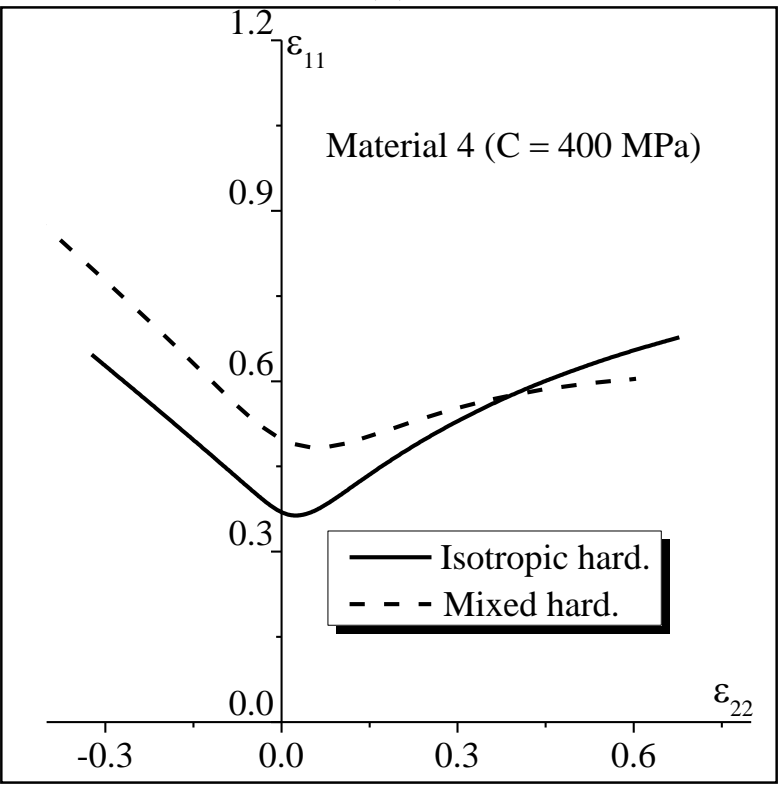

(d)

Fig. 4 Effect of kinematic hardening on the FLDs of freestanding metal layer: (a) Material 1;

(b) Material 2; (c) Material 3; (d) Material 4.

The impact of the initial imperfection factor $\xi_{\mathrm{I}}$ on the shape and the level of the FLDs for both hardening models is depicted in Fig. 5. In this figure, two different initial imperfection factors are considered in the simulations: $10^{-3}$ (curves with solid lines) and $10^{-2}$ (curves with dashed lines). As well known from several previous works (see, for instance, $[8,26]$ ), the effect of increasing the initial imperfection is essentially to shift the FLD downwards. Thus, the level of the FLD decreases when the value of the initial imperfection factor $\xi_{\mathrm{I}}$ increases. 
For both hardening models, the imperfection plays a destabilizing role that precipitates the occurrence of strain localization. It is also observed from these figures that the impact of the hardening model on the necking strains is consistently the same, whatever the value of the initial imperfection factor. In other words, for the two imperfection values $\xi_{\mathrm{I}}$, the limit strain increases with the kinematic hardening parameter $\mathrm{C}$ for strain paths ranging from -0.5 to 0.5 , while it decreases in the neighborhood of equibiaxial tension (i.e., $\rho \in[0.5,1]$ ). Although similar trends are observed, it should be noted that the difference between the FLD predictions yielded by the isotropic and mixed hardening models increases with decreasing the initial imperfection. For the sake of conciseness, isotropic hardening (resp. mixed hardening) is referred to as $\mathrm{IH}$ (resp. $\mathrm{MH}$ ) in Fig. 5.

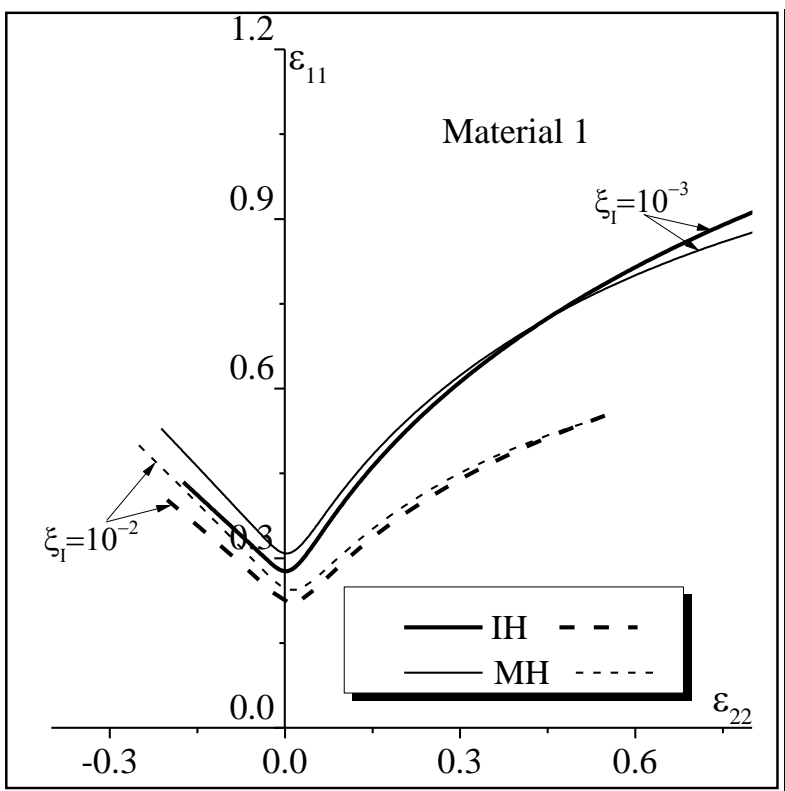

(a)

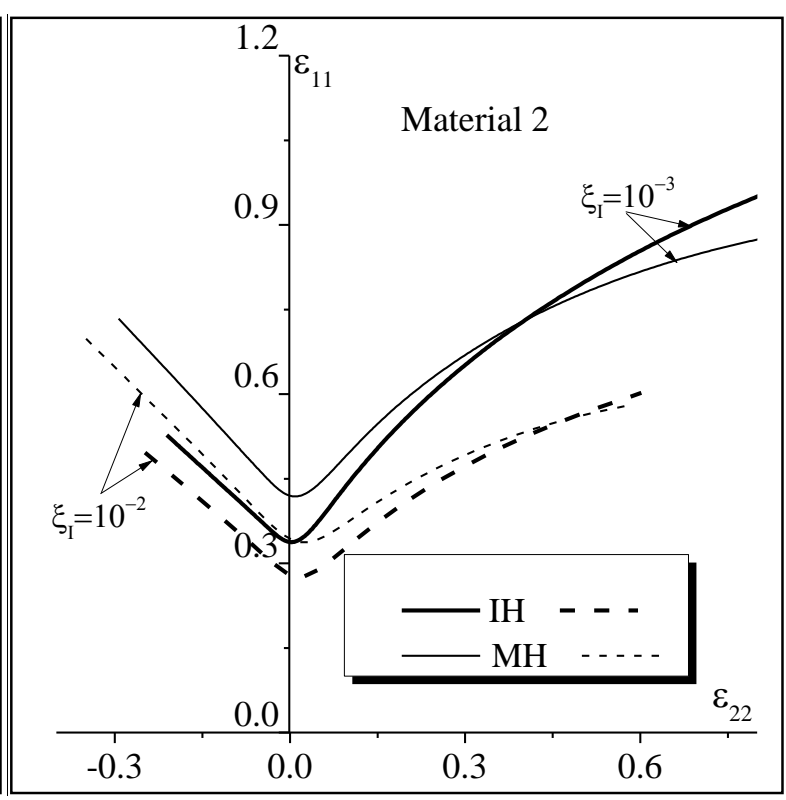

(b) 


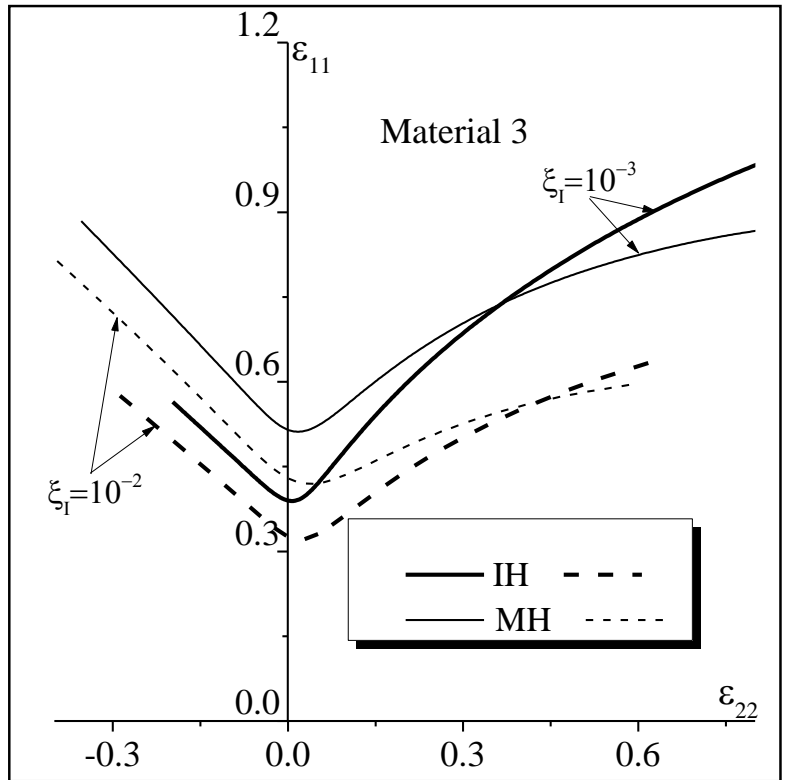

(c)

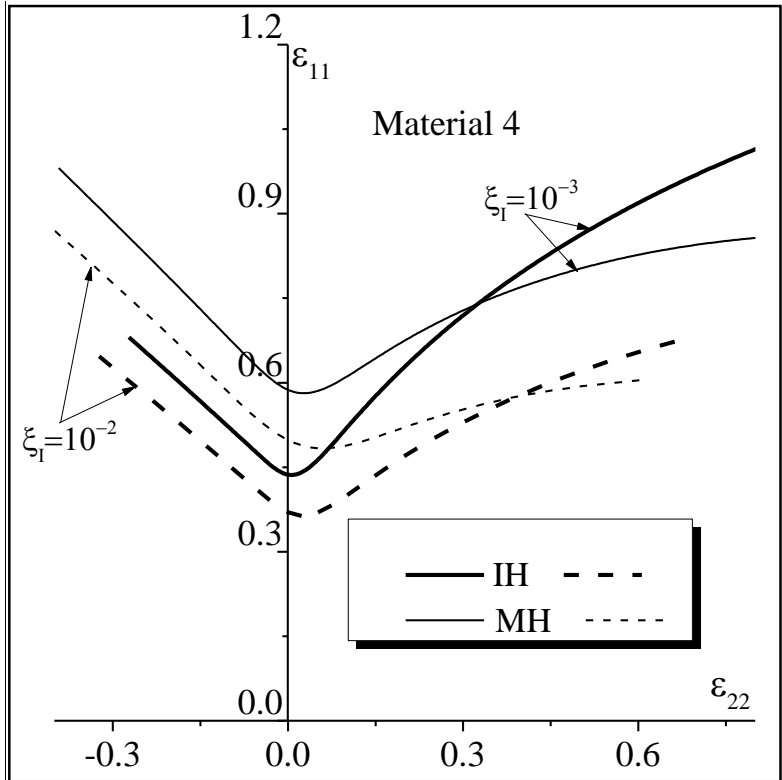

(d)

Fig. 5 Effect of the initial imperfection factor on the FLDs of freestanding metal layer: (a)

$$
\text { Material 1; (b) Material 2; (c) Material 3; (d) Material } 4 .
$$

\subsection{Metal/Elastomer bilayer}

In this section, a bilayer combination is considered: a metal layer supported by an elastomer substrate. In all calculations reported in this section, the material parameters of the metal layer are those given in Table 1 . The shear modulus $\mu$ of the elastomer layer is fixed to $22 \mathrm{MPa}$. This latter choice is based on data for polyurea [31].

Similar to the case of a freestanding metal layer, we first consider the plane-strain case $(\rho=0)$. In this case, an analytical formula, comparable to Eq. (21), can be derived after some straightforward developments

$$
\begin{aligned}
& \mathrm{e}^{-\varepsilon_{11}^{\mathrm{B}}}\left(2 \mathrm{~h}_{\mathrm{I}}^{\mathrm{B}}\left(\mathrm{C} \varepsilon_{11}^{\mathrm{B}}+\frac{2^{\mathrm{n}} \mathrm{K}\left(\varepsilon_{11}^{\mathrm{B}}\right)^{\mathrm{n}}}{3^{\frac{\mathrm{n}+1}{2}}}\right)+\mu \mathrm{H}_{\mathrm{I}}^{\mathrm{B}}\left(\mathrm{e}^{2 \varepsilon_{11}^{\mathrm{B}}}-\mathrm{e}^{-2 \varepsilon_{11}^{\mathrm{B}}}\right)\right) \\
= & \mathrm{e}^{-\varepsilon_{11}^{\mathrm{S}}}\left(2 \mathrm{~h}_{\mathrm{I}}^{\mathrm{S}}\left(\mathrm{C} \varepsilon_{11}^{\mathrm{S}}+\frac{2^{\mathrm{n}} \mathrm{K}\left(\varepsilon_{11}^{\mathrm{S}}\right)^{\mathrm{n}}}{3^{\frac{\mathrm{n}+1}{2}}}\right)+\mu \mathrm{H}_{\mathrm{I}}^{\mathrm{S}}\left(\mathrm{e}^{2 \varepsilon_{11}^{\mathrm{S}}}-\mathrm{e}^{-2 \varepsilon_{11}^{\mathrm{S}}}\right)\right)^{.}
\end{aligned}
$$

Again, for each prescribed value of $\varepsilon_{11}^{B}$, Eq. (22) is solved iteratively to determine the corresponding value of $\varepsilon_{11}^{\mathrm{S}}$. In this process, the prescribed strain component $\varepsilon_{11}^{\mathrm{B}}$ is varied 
between 0 and 1 . The initial imperfection ratio $\xi_{\mathrm{I}}$ is fixed to $10^{-2}$. To emphasize the effect of the elastomer layer, Fig. 6 compares the evolution of $\varepsilon_{11}^{\mathrm{B}} / \varepsilon_{11}^{\mathrm{S}}$ as a function of $\varepsilon_{11}^{\mathrm{S}}$, with and without addition of an elastomer layer, for the different materials defined in Table 1. For the sake of clarity, only the results corresponding to mixed hardening are reported in Fig. 6. It is clearly shown from this figure that, for this particular plane-strain loading path, the addition of an elastomer layer allows enhancing the ductility of the resulting bilayer.

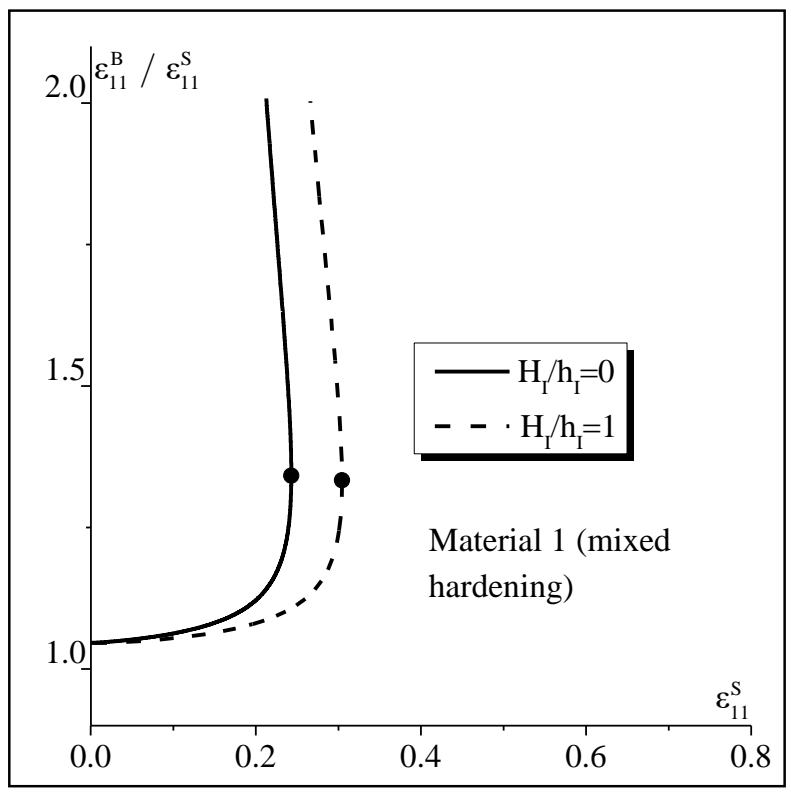

(a)

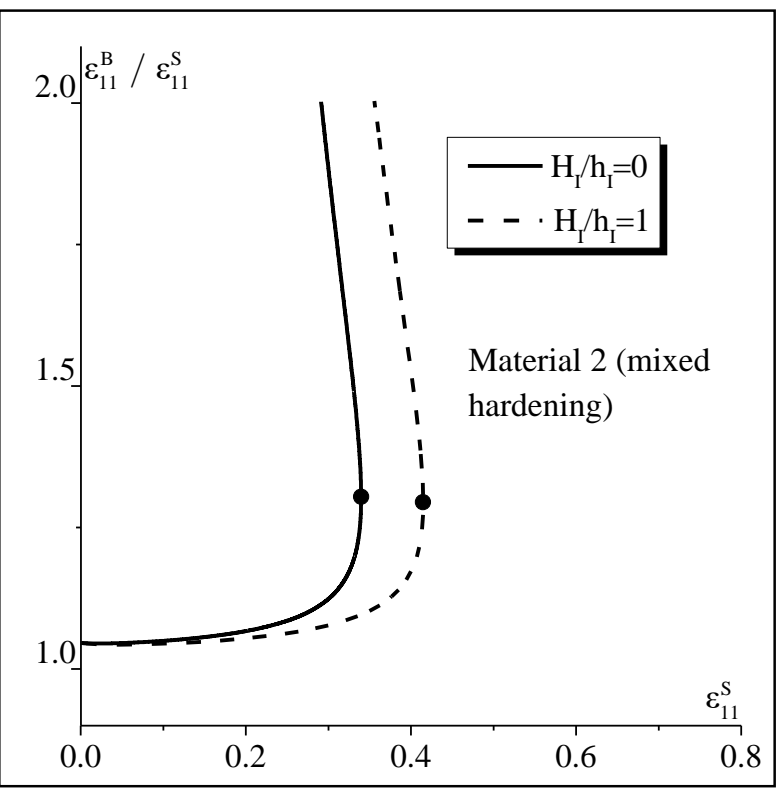

(b) 


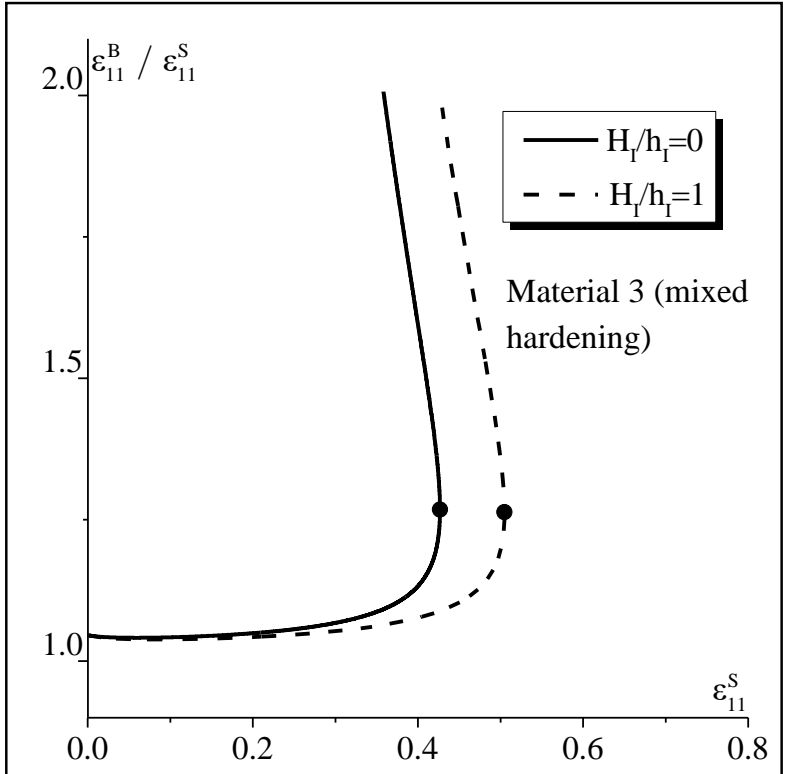

(c)

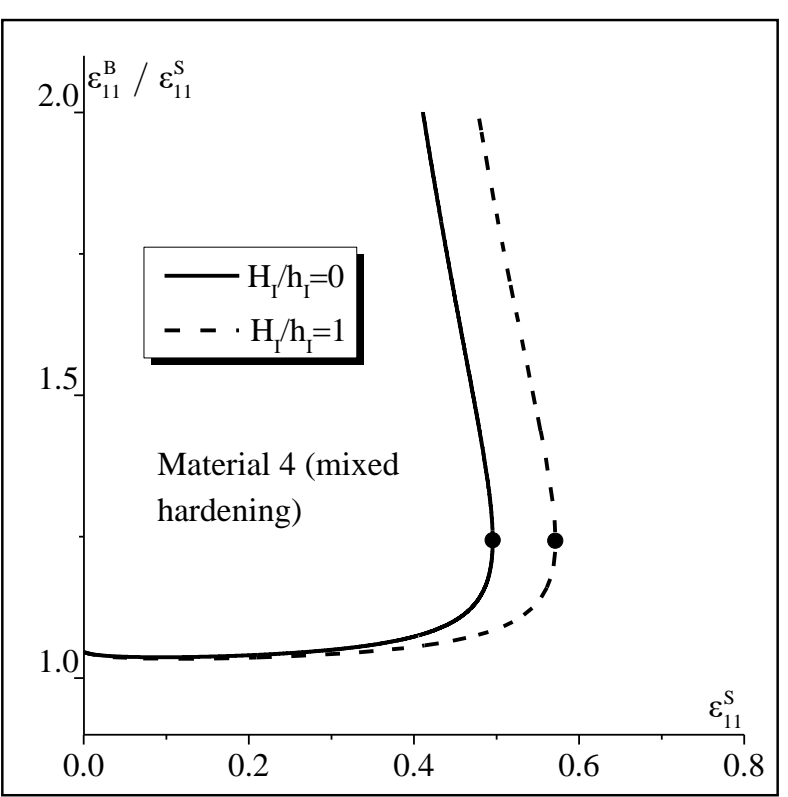

(d)

Fig. 6 Evolution of strain ratio $\varepsilon_{11}^{\mathrm{B}} / \varepsilon_{11}^{\mathrm{S}}$ as a function of $\varepsilon_{11}^{\mathrm{S}}$ for the plane-strain state (metal/elastomer bilayer): (a) Material 1 (mixed hardening); (b) Material 2 (mixed hardening); (c) Material 3 (mixed hardening); (d) Material 4 (mixed hardening).

Several simulations are carried out in order to further investigate the effect of the thickness of the elastomer layer, relative to that of the metal layer, on the ductility of the bilayer. The results are reported in Fig. 7 for an initial imperfection factor $\xi_{\mathrm{I}}$ equal to $10^{-2}$. These simulations demonstrate that the effect of the substrate layer on the ductility of the bilayer is quite significant and confirm the previously reported results regarding the positive effect of the elastomer layer on the necking limit. Fig. 7 shows that the limit strains increase as the ratio of the initial thicknesses $H_{I} / h_{I}$ increases, revealing that a relatively thicker substrate leads to more necking retardation. The above results and observations are valid for all different materials modeled with both hardening descriptions. 


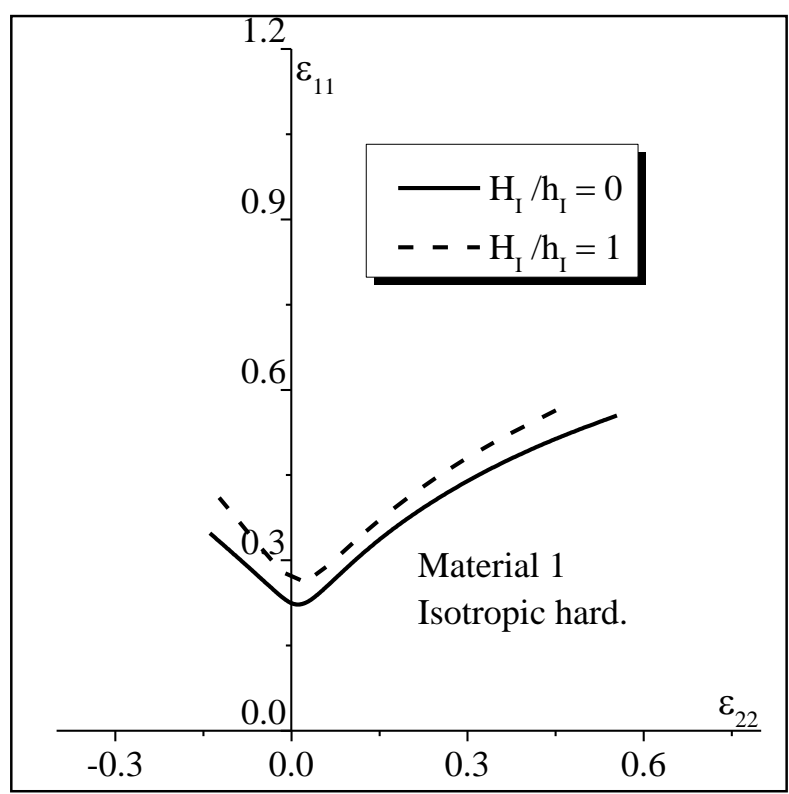

(a)

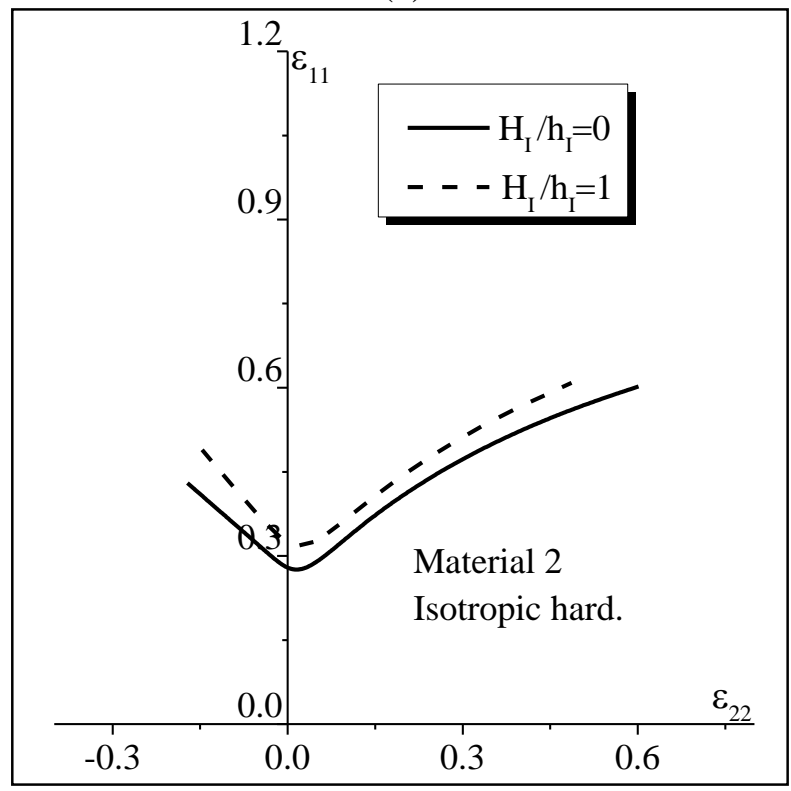

(c)

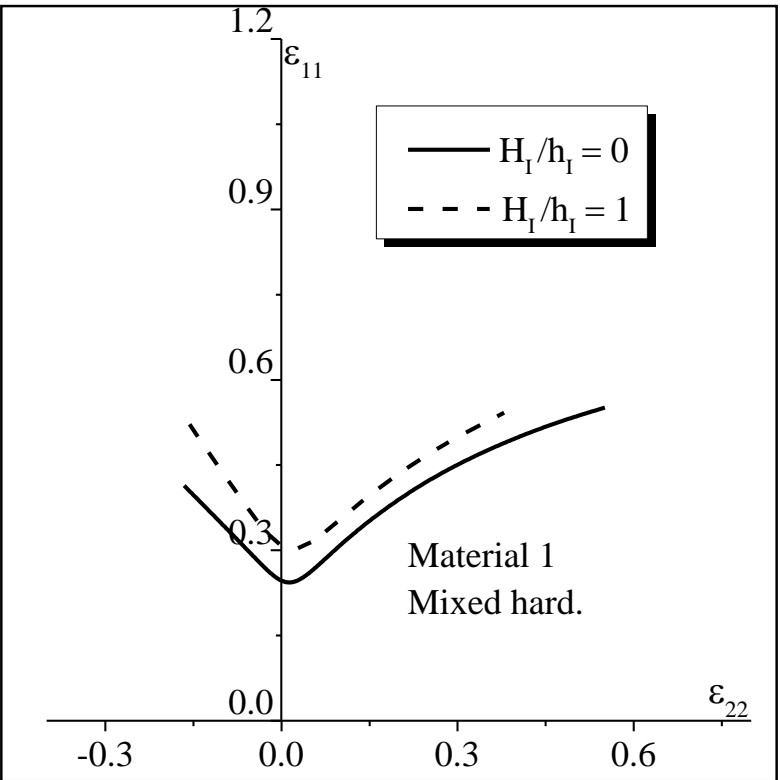

(b)

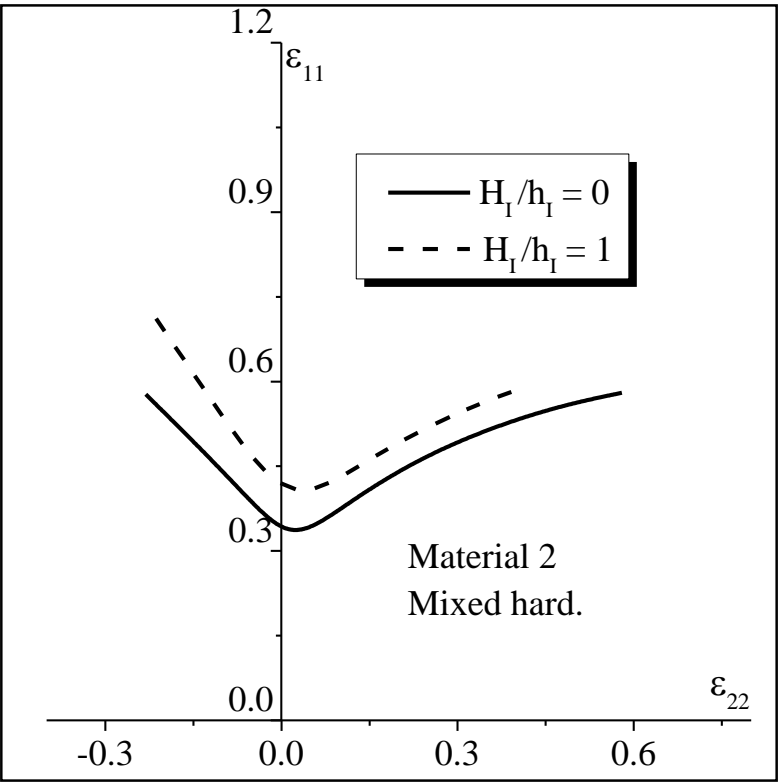

(d) 


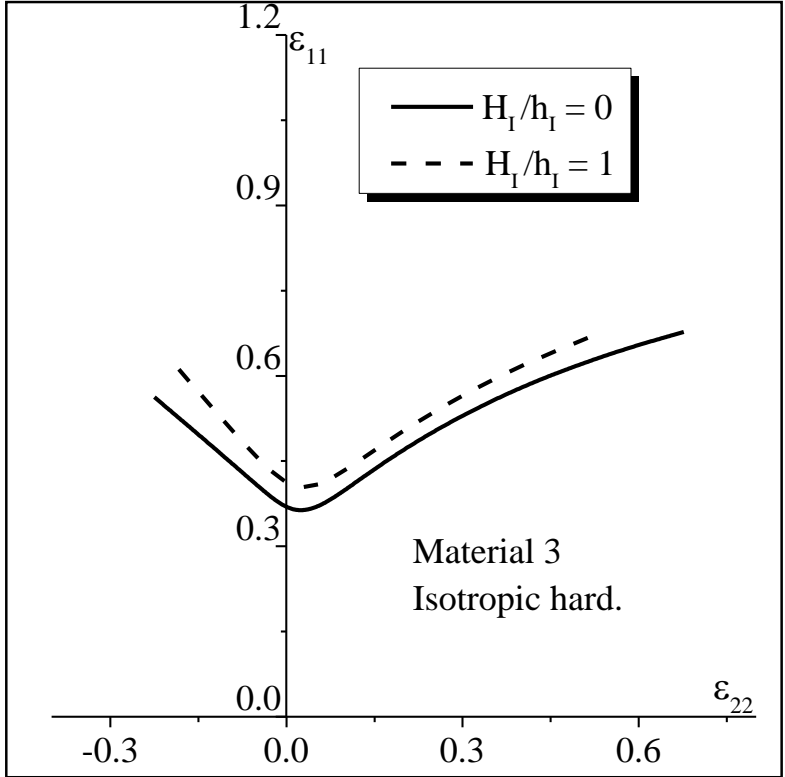

(e)

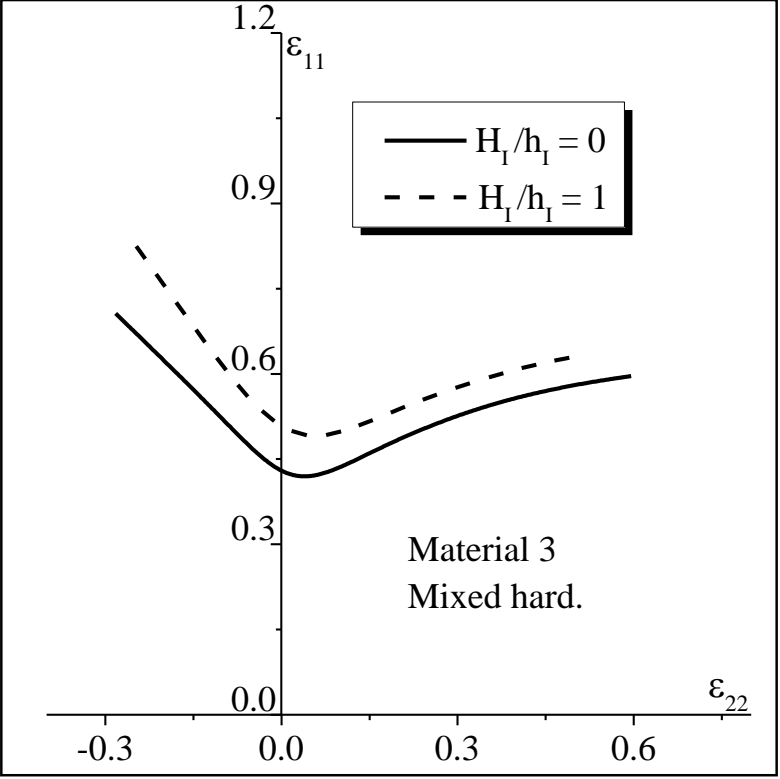

(f)

Fig. 7 Effect of the thickness ratio $\mathrm{H}_{\mathrm{I}} / \mathrm{h}_{\mathrm{I}}$ on the FLDs of metal/elastomer bilayer: (a)

Material 1 (Isotropic hardening); (b) Material 1 (Mixed hardening); (c) Material 2 (Isotropic hardening); (d) Material 2 (Mixed hardening); (e) Material 3 (Isotropic hardening); (f) Material 3 (Mixed hardening).

\section{Conclusions}

The forming limits for freestanding metal layers and substrate-supported metal layers have been numerically determined using both isotropic and mixed hardening models. The conclusions based upon the present work are given as follows:

- The limit strain mostly increases with the back-stress, when modeled with the Prager law, except for loading paths close to equibiaxial tension, as shown in Fig. 2. For moderate values of the kinematic hardening parameter $\mathrm{C}$, the difference between the FLDs predicted by isotropic and mixed hardening models is not very significant.

- For both hardening models, the presence of an elastomer layer enhances substantially the necking limit of the metal/elastomer bilayer. This neck retardation is due to the mechanical constraint of the substrate to the metal deformation. 


\section{References}

[1] Keeler, S.P., and Backofen, W.A., 1963, "Plastic Instability and Fracture in Sheets Stretched Over Rigid Punches," Transaction of the American Society for Metals (ASM), 56(1), pp. 25-48.

[2] Goodwin, G.M., 1968, "Application of Strain Analysis to Sheet Metal Forming Problems in the Press Shop," La Metallurgia Italiana, 60, pp. 764-774.

[3] Abed-Meraim, F., Balan, T., and Altmeyer, G., 2014, "Investigation and Comparative Analysis of Plastic Instability Criteria: Application to Forming Limit Diagrams," Int. J. Adv. Manuf. Technol., 71, pp. $1247-1262$.

[4] Jaamialahmadi, A., and Kadkhodayan, M., 2011, “An Investigation Into the Prediction of Forming Limit Diagrams for Normal Anisotropic Material Based on Bifurcation Analysis," J. Appl. Mech., 78(3), pp. 031006-031016.

[5] Jaamialahmadi, A., and Kadkhodayan, M., 2012, “A Modified Storen-Rice Bifurcation Analysis of Sheet Metal Forming Limit Diagrams,” J. Appl. Mech., 79(6), pp. 1004-1014.

[6] Chow, C.L., Yang, J., and Chu, E., 2002, "Prediction of Forming Limit Diagram Based on Damage Coupled Kinematic-Isotropic Hardening Model Under Nonproportional Loading,” J. Eng. Mater. Technol., 124(2), pp. 259-265.

[7] Jalali Aghchai, A., Shakeri, M., and Mollaei Dariani, B., 2013, "Influences of Material Properties of Components on Formability of Two-layer Metallic Sheets,” Int. J. Adv. Manuf. Technol., 66, pp. $809-823$.

[8] Hutchinson, J.W., and Neale, K.W., 1978, Sheet Necking-II, Time-Independent Behavior, Mechanics of Sheet Metal Forming, D. P. Koistinen and N. M. Wang, eds., Plenum, New York, pp. $127-153$.

[9] Ghosh, A., 1977, "A Tensile Instability and Necking in Materials with Strain Hardening and Strain-Rate Hardening,” Acta. Metall., 25, pp. 1413-1424.

[10] Hutchinson, J.W., and Neale, K.W., 1978, Sheet Necking-III. Strain-rate Effects, D. P. Koistinen and N. M. Wang, eds., Plenum, New York, pp. 269-285. 
[11] Neale, K.W., and Chater, E., 1980, "Limit Strain Predictions for Strain-rate Sensitive Anisotropic Sheets,” Int. J. Mech. Sci., 22, pp. 563-574.

[12] Cao, J., Yao, H., Karafillis, A., and Boyce, M.C., 2000, "Prediction of Localized Thinning in Sheet Metal using a General Anisotropic Yield Criterion,” Int. J. Plast., 16, pp. 1105-1129.

[13] Kuroda, M., and Tvergaard, V., 2000, "Forming Limit Diagrams for Anisotropic Metal Sheets with Different Yield Criteria,” Int. J. Solids. Struct., 37, pp. 5037-5059.

[14] Haddag, B., Abed-Meraim, F., and Balan, T., 2009, "Strain Localization Analysis using a Large Deformation Anisotropic Elastic-plastic Model Coupled with Damage,” Int. J. Plast., 25, pp. 19701995.

[15] Mansouri, L.Z., Chalal, H., and Abed-Meraim, F., 2014, "Ductility Limit Prediction using a GTN Damage Model Coupled with Localization Bifurcation Analysis," Mech. Mater., 76, pp. 64-92.

[16] Tvergaard, V., 1978, "Effect of Kinematic Hardening on Localized Necking in Biaxially Stretched Sheets,” Int. J. Mech. Sci., 20, pp. 651-658.

[17] He, J., Cedric Xia, Z., Zhu, X., Zeng, D., and Li, S., 2013, "Sheet metal forming limits under stretch-bending with anisotropic hardening," Int. J. Mech. Sci., 75, pp. 244-256.

[18] He, J., Zeng, D., Zhu, X., Cedric Xia, Z., and Li, S., 2014, "Effect of nonlinear strain paths on forming limits under isotropic and anisotropic hardening,” Int. J. Solids. Struct., 51, pp. 402-415.

[19] Hommel, M., and Kraft, O., 2001, "Deformation Behavior of Thin Copper Films on Deformable Substrates," Acta. Mater., 49, pp. 3935-3947.

[20] Huang, H.B., and Spaepen, F., 2000, "Tensile testing of free-standing $\mathrm{Cu}, \mathrm{Ag}$ and $\mathrm{Al}$ thin films and Ag/Cu multilayers," Acta. Mater., 48, pp. 3261-3269.

[21] Lu, N., Wang, X., Suo, Z., and VIassak, J., 2007, "Metal films on polymer substrates stretched beyond 50\%,” Appl. Phys. Lett., 91, 221909.

[22] Morales, S.A., Albrecht, A.B., Zhang, H., Liechti, K.M., and Ravi-Chandar, K., 2011, "On the dynamics of localization and fragmentation: V. Response of polymer coated Al 6061-O tubes,” Int. J. Fract., 172, pp. 161-185. 
[23] Guduru P.R., Bharathi M.S., and Freund L.B., 2006, "The influence of a surface coating on the high-rate fragmentation of a ductile material," Int. J. Fract., 137, pp 89-108.

[24] Jia, Z., and Li, T., 2013, "Necking limit of substrate-supported metal layers under biaxial in-plane loading,” Int. J. Plast., 51, pp. 65-79.

[25] Stören, S., and Rice, J. R., 1975, “Localized Necking in Thin Sheets,” J. Mech. Phys. Solids, 23, pp. $421-441$.

[26] Ben Bettaieb, M., and Abed-Meraim, F., 2015, "Investigation of Localized Necking in Substratesupported Metal Layers: Comparison of Bifurcation and Imperfection Analyses,” Int. J. Plast., 65, pp. $168-190$.

[27] Marciniak, Z., and Kuczynski, K., 1967, "Limit Strains in the Processes of Stretch-forming Sheet Metal,” Int. J. Mech. Sci., 9, pp. 609-620.

[28] Hollomon, J.H., 1945, “Tensile Deformation,” Trans. ASM., 162, pp. 268-290.

[29] Prager, W., 1955, "The theory of plasticity - a survey of recent achievements," Proc. Inst. of Mech. Engrg. London, England, 169, pp. 41-57.

[30] Hunter, S.C., 1979, "Some Exact Solutions in the Theory of Finite Elasticity for Incompressible Neo-Hookean Materials,” Int. J. Mech. Sci., 21, pp. 203-211.

[31] Amirkhizi, A.V, Isaacs, J., McGee, J., and Nemat-Nasser, S., 2006, “An Experimentally-Based Viscoelastic Constitutive Model for Polyurea Including Pressure and Temperature Effects," Philos. Mag., 86, pp. 5847-5866. 